\title{
Global patterns of twelve mineral elements in leaf litter
}

\author{
Yajun $\mathrm{Xie}^{1}$, Yonghong Xie ${ }^{2}$, and xiao hua-yun ${ }^{1}$ \\ ${ }^{1}$ East China University of Technology \\ ${ }^{2}$ Institute of Subtropical Agriculture Chinese Academy of Sciences
}

August 7, 2020

\begin{abstract}
Litters carry out the cycling and storage of multiple nutrients and heavy metals, and thus litter mineral elements sharp many key ecosystem processes. Understanding the global geographic patterns of litter elements is needed for plant nutrition and biogeochemical models, but such knowledge is largely limited to $\mathrm{N}$ and P. By compiling data on 12 mineral elements in leaf litter from 1, 666 species, we show that elements differed largely in their retranslocation efficiencies and among plant functional types. Elements in leaf litter responded to latitude in a similar manor as those in green leaves, except for N. Disproportionate resorption acted as a negative feedback and caused leaf litter $\mathrm{N}$ to decline with latitude, a trend contrary to green leaf $\mathrm{N}$; litter $\mathrm{P}$ increased with latitude as predicted by the Plant Physiological Hypotheses. The rest elements generally declined with latitude, supporting the Temperature-Biogeochemistry Hypotheses. Soil nutrients likely had indirect effects on these latitudinal patterns via controls on green leaves, while woody plant distribution per se had modest effects. Overall, we suggest that fundamental constraints on plant nutrient conservation and usage strategies lead to predictable global-scale patterns in multiple litter elements.
\end{abstract}

\section{Hosted file}

manuscript 2020.doc available at https://authorea.com/users/349520/articles/474507-globalpatterns-of-twelve-mineral-elements-in-leaf-litter 